\title{
Effect of Low and High Dose Sugammadex on the Coagulation and Fibrinolytic System in Rats
}

\author{
Nilay Taş, ${ }^{1}$ Özgür Yağan, ${ }^{1}$ Tevfik Noyan, ${ }^{2}$ Sema Nur Ayyıldız, ${ }^{2}$ Y. Burcu Üstün, ${ }^{3}$ \\ Özgül Gözlükaya, ${ }^{4}$ and Serhat Kocamanoğlu ${ }^{3}$
}

\author{
${ }^{1}$ Department of Anesthesiology, Faculty of Medicine, Ordu University, 52100 Ordu, Turkey \\ ${ }^{2}$ Department of Biochemistry, Faculty of Medicine, Ordu University, 52100 Ordu, Turkey \\ ${ }^{3}$ Department of Anesthesiology, Faculty of Medicine, Ondokuz Mayıs University, 55139 Samsun, Turkey \\ ${ }^{4}$ Department of Biochemistry, Ordu State Hospital, 52100 Ordu, Turkey
}

Correspondence should be addressed to Nilay Taş; drnil.anest@hotmail.com

Received 19 April 2015; Accepted 25 May 2015

Academic Editor: Ming-Hwang Shyr

Copyright (c) 2015 Nilay Taş et al. This is an open access article distributed under the Creative Commons Attribution License, which permits unrestricted use, distribution, and reproduction in any medium, provided the original work is properly cited.

\begin{abstract}
Background. Sugammadex is a new reversal agent that has entered use recently. It is known that with sugammadex some changes in coagulation parameters occur without documented clinical results. Aim of the Work. The objective of this study was to identify effects of sugammadex on liver functions, coagulation, and fibrinolytic systems. Methods. Thirty-six rats were randomized into six groups: Group I, control; Group II, rocuronium group; Group III, sugammadex administered in $16 \mathrm{mg} \mathrm{kg}^{-1} \mathrm{dose}$ Group IV, sugammadex administered in $96 \mathrm{mg} \mathrm{kg}^{-1}$ dose; Group V, rocuronium and sugammadex administered in $16 \mathrm{mg} \mathrm{kg}^{-1}$ dose; and Group VI, rocuronium and sugammadex administered in $96 \mathrm{mg} \mathrm{kg}^{-1}$ dose. After 120 minutes, blood samples were obtained for prothrombin time, activated partial thromboplastin time, D-dimer, fibrinogen, aspartate aminotransferase, alanine aminotransferase, albumin, platelet, and mean platelet volume analyses. Results. Compared to the control group, in all groups measured parameters did not show any effect from a statistical viewpoint either due to the administered drugs alone or due to interaction effects. Conclusion. The conclusion was reached that administration of sugammadex in rats did not have any significant effect on the fibrinolytic system, coagulation parameters, and liver function.
\end{abstract}

\section{Introduction}

Acetylcholinesterase inhibitors, used to reverse the effects of nondepolarizing neuromuscular blockers, have important disadvantages such as residual block and hemodynamic side effects $[1,2]$. The most important reasons for choosing sugammadex, a gamma cyclodextrin derivative which has entered use in recent years, are its superior properties during extubation and recovery stages and low risk of residual block [3].

Though it has no significant side effect reported from clinical use, it is reported that sugammadex causes a range of changes in coagulation parameters $[4,5]$. There are publications recommending the effects of different doses of sugammadex on hemorrhage and coagulation should be clinically researched [6]. In this study low and high dose sugammadex were used to reverse neuromuscular block, with the aim of researching the effects of sugammadex on liver function, coagulation, and fibrinolytic system.

\section{Materials and Methods}

2.1. Animals and Study Groups. This experimental study was approved by Ondokuz Mayss University Animal Care and Ethics Committee (2013/35). Female Sprague-Dawley rats ( $n$ : 36, weight: $200-250 \mathrm{~g}$ ) were randomized into six groups. There was no mortality in the study animals and all rats were stable throughout the study period. Rats were anesthetized with ketamine hydrochloride (i.m. $60 \mathrm{mg} \mathrm{kg}^{-1}$ ) and xylazine (i.m. $10 \mathrm{mg} \mathrm{kg}^{-1}$ ) and anesthesia was maintained with xylazine (i.m. $10 \mathrm{mg} \mathrm{kg}^{-1}$ per hour). The rats were placed in supine position with their extremities on the operating table: Group I, control; Group II, rocuronium administered in dose 
TABLE 1: Descriptive statistics for PLT and MPV parameters according to group and administered agents.

\begin{tabular}{|c|c|c|c|c|c|c|c|c|c|}
\hline \multirow{2}{*}{ Parameters } & \multirow{2}{*}{ Groups } & \multirow{2}{*}{$N$} & \multirow{2}{*}{ Mean } & \multirow{2}{*}{$\mathrm{SD}^{*}$} & \multirow{2}{*}{ Min } & \multirow{2}{*}{ Max } & \multicolumn{3}{|c|}{$p$ values } \\
\hline & & & & & & & S & $\mathrm{R}$ & $\mathrm{S} \times \mathrm{R}$ \\
\hline \multirow{7}{*}{ PLT } & Control (I) & 6 & 726000 & 103935 & 596000 & 867000 & \multirow{7}{*}{0,765} & \multirow{7}{*}{0,840} & \multirow{7}{*}{0,380} \\
\hline & $\mathrm{R}(\mathrm{II})$ & 6 & 638800 & 209163 & 412000 & 886000 & & & \\
\hline & S_16 (III) & 6 & 563800 & 126628 & 424000 & 717000 & & & \\
\hline & S_96 (IV) & 6 & 650200 & 193688 & 362000 & 886000 & & & \\
\hline & R + S_16 (V) & 6 & 690200 & 243721 & 416000 & 993000 & & & \\
\hline & $\mathrm{R}+\mathrm{S} \_96(\mathrm{VI})$ & 6 & 648800 & 66717 & 567000 & 739000 & & & \\
\hline & Total & 36 & 652967 & 162129 & 362000 & 993000 & & & \\
\hline \multirow{7}{*}{ MPV } & Control (I) & 6 & 5,55 & 0,25 & 5,34 & 5,84 & \multirow{7}{*}{0,819} & \multirow{7}{*}{0,895} & \multirow{7}{*}{0,602} \\
\hline & $\mathrm{R}(\mathrm{II})$ & 6 & 5,77 & 0,38 & 5,34 & 6,22 & & & \\
\hline & S_16 (III) & 6 & 5,70 & 0,56 & 5,24 & 6,66 & & & \\
\hline & S_96 (IV) & 6 & 5,53 & 0,71 & 4,62 & 6,53 & & & \\
\hline & R + S_16 (V) & 6 & 5,43 & 0,53 & 4,68 & 6,11 & & & \\
\hline & $\mathrm{R}+\mathrm{S} \_96(\mathrm{VI})$ & 6 & 5,49 & 0,68 & 4,67 & 6,45 & & & \\
\hline & Total & 36 & 5,58 & 0,51 & 4,62 & 6,66 & & & \\
\hline
\end{tabular}

${ }^{*}$ SD: standard deviation.

PLT: platelet.

MPV: mean platelet volume.

$1 \mathrm{mg} \mathrm{kg}^{-1}$ i.v. (Esmeron, N. V. Organon, Oss/Netherlands); Group III, sugammadex administered in dose $16 \mathrm{mg} \mathrm{kg}^{-1}$ i.v. (Bridion, N. V. Organon, Kloosterstraat 6, Oss/Netherlands); Group IV, sugammadex administered in dose $96 \mathrm{mg} \mathrm{kg}^{-1}$ i.v.; Group V, $1 \mathrm{mg} \mathrm{kg}^{-1}$ rocuronium and $16 \mathrm{mg} \mathrm{kg}^{-1}$ sugammadex i.v.; and Group VI, $1 \mathrm{mg} \mathrm{kg}^{-1}$ rocuronium and $96 \mathrm{mg} \mathrm{kg}^{-1}$ sugammadex i.v. Group I was given $1 \mathrm{~mL}$ physiological serum i.v. of equal volume to the rest of the groups. After drug administration, the animals were intubated in Groups II, V, and VI and they were ventilated with a breathing circuit. In Groups V and VI, rats received rocuronium and following endotracheal intubation sugammadex was administered without delay. Upon maintenance of the spontaneous ventilation, the rats were extubated and returned to their environment. The groups that were not intubated waited the same length of time for spontaneous respiration as the other groups that were intubated. The rats were rested for 120 minutes (sugammadex has an elimination half-life of 100-150 minutes) after extubation and blood samples were obtained into citrate including tubes for prothrombin time (PT), activated partial thromboplastin time (aPTT), D-dimer, fibrinogen, aspartate aminotransferase (AST), alanine aminotransferase (ALT), and albumin measurements and other samples were obtained into K2EDTA including tubes for platelet (PLT) and mean platelet volume (MPV) measurements by cardiac puncture. The blood samples were centrifuged at $2000 \times \mathrm{g}$ for $10 \mathrm{~min}$ at $4^{\circ} \mathrm{C}$ and plasma samples were studied immediately. PT, aPTT, and fibrinogen measurements were performed by original reagent on ERBA analyzer. AST, ALT, and albumin measurements were performed colorimetrically on ABBOT C8000 autoanalyzer and D-dimer measurements were also performed using the ELISA method. Platelet (PLT) and mean platelet volume (MPV) measurements were performed on ABBOT Cell Dyne analyzer.
2.2. Statistical Analyses. According to the results of the Levene test $(p>0.05)$ and Shapiro Wilk test $(p>0.05)$ for equality of variances and the normality assumption, respectively, an analysis of variance was performed in a completely randomized design with a $3 \times 2$ factorial arrangement of treatments (S and R levels): $\widehat{Y}_{i}=\mu+\mathrm{S}_{i}+\mathrm{V}_{j}+\mathrm{SV}_{i j}+e_{i j}$ where $\widehat{Y}_{i}$ is observation value; $\mu$ is the overall mean; $S_{i}$ is the effect of the $i$ th $S$ treatment $(1=$ without $S, 2=$ with low $S, 3=$ with high $S$ ); $\mathrm{V}_{j}$ is the effect of the $j$ th $\mathrm{R}$ treatment $(1=$ without $\mathrm{R}, 2=$ with $\mathrm{R}) ; \mathrm{SV}_{i j}$ is the effect of interaction between $\mathrm{S}$ and $\mathrm{R}$; and $e_{i j} k=$ residual error. Then, the Tukey HSD multiple comparison test was applied to determine any further differences among the groups. Significance was evaluated at $p<0.05$ for all tests. Statistical analyses were performed using SPSS 20.0 (SPSS, Inc., Chicago, Illinois).

\section{Results}

Descriptive statistical data from all groups are presented in Tables 1, 2, 3, and 4. We did not find a significant change in PLT and MPV counts in any of the groups given low or high dose sugammadex compared with the control group. Again in terms of PT, aPTT, fibrinogen, and D-dimer levels, there was no significant difference between the groups. In our study when the markers of liver function of AST, ALT, and albumin levels are examined, there was no difference found between the groups. There was no statistically significant difference between all these variables; $p$ values ranged between 0.184 and $0.990(p>0.05)$.

\section{Discussion}

Nondepolarizing neuromuscular blockers are used routinely in modern anesthetic practice in the whole world [7]. With 
TABLE 2: Descriptive statistics for PT and aPTT parameters according to group and administered agents.

\begin{tabular}{|c|c|c|c|c|c|c|c|c|c|}
\hline \multirow{2}{*}{ Parameters } & \multirow{2}{*}{ Groups } & \multirow{2}{*}{$N$} & \multirow{2}{*}{ Mean } & \multirow{2}{*}{$\mathrm{SD}^{*}$} & \multirow{2}{*}{ Min } & \multirow{2}{*}{$\operatorname{Max}$} & \multicolumn{3}{|c|}{$p$ values } \\
\hline & & & & & & & S & $\mathrm{R}$ & $\mathrm{S} \times \mathrm{R}$ \\
\hline \multirow{7}{*}{ PT } & Control (I) & 6 & 17,38 & 3,72 & 12,00 & 21,40 & \multirow{7}{*}{0,671} & \multirow{7}{*}{0,452} & \multirow{7}{*}{0,356} \\
\hline & $\mathrm{R}(\mathrm{II})$ & 6 & 20,57 & 1,61 & 18,70 & 22,50 & & & \\
\hline & S_16 (III) & 6 & 17,13 & 3,15 & 11,80 & 19,80 & & & \\
\hline & S_96 (IV) & 6 & 18,30 & 4,50 & 10,00 & 22,30 & & & \\
\hline & R + S_16 (V) & 6 & 18,88 & 6,60 & 10,00 & 30,30 & & & \\
\hline & $\mathrm{R}+\mathrm{S} \_96(\mathrm{VI})$ & 6 & 16,58 & 4,08 & 10,60 & 20,40 & & & \\
\hline & Total & 36 & 18,14 & 4,13 & 10,00 & 30,30 & & & \\
\hline \multirow{7}{*}{ aPTT } & Control (I) & 6 & 33,07 & 8,39 & 20,00 & 41,40 & \multirow{7}{*}{0,990} & \multirow{7}{*}{0,221} & \multirow{7}{*}{0,878} \\
\hline & $\mathrm{R}(\mathrm{II})$ & 6 & 28,12 & 9,95 & 20,10 & 41,10 & & & \\
\hline & S_16 (III) & 6 & 31,73 & 8,76 & 22,60 & 46,30 & & & \\
\hline & S_96 (IV) & 6 & 33,17 & 8,11 & 23,40 & 45,10 & & & \\
\hline & $\mathrm{R}+\mathrm{S} \_16(\mathbf{V})$ & 6 & 30,18 & 7,16 & 22,00 & 40,20 & & & \\
\hline & $\mathrm{R}+\mathrm{S} \_96(\mathrm{VI})$ & 6 & 28,97 & 8,71 & 20,30 & 42,10 & & & \\
\hline & Total & 36 & 30,87 & 8,16 & 20,00 & 46,30 & & & \\
\hline
\end{tabular}

${ }^{*}$ SD: standard deviation.

PT: prothrombin time.

aPTT: activated partial thromboplastin time.

TABLE 3: Descriptive statistics for fibrinogen and D-dimer parameters according to group and administered agents.

\begin{tabular}{|c|c|c|c|c|c|c|c|c|c|}
\hline \multirow{2}{*}{ Parameters } & \multirow{2}{*}{ Groups } & \multirow{2}{*}{$N$} & \multirow{2}{*}{ Mean } & \multirow{2}{*}{$\mathrm{SD}^{*}$} & \multirow{2}{*}{ Min } & \multirow{2}{*}{ Max } & \multicolumn{3}{|c|}{$p$ values } \\
\hline & & & & & & & S & $\mathrm{R}$ & $\mathrm{S} \times \mathrm{R}$ \\
\hline \multirow{7}{*}{ Fibrinogen } & Control (I) & 6 & 133,17 & 23,85 & 109,00 & 172,00 & \multirow{7}{*}{0,993} & \multirow{7}{*}{0,803} & \multirow{7}{*}{0,795} \\
\hline & $\mathrm{R}(\mathrm{II})$ & 6 & 132,33 & 47,95 & 81,00 & 209,00 & & & \\
\hline & S_16 (III) & 6 & 139,67 & 29,34 & 96,00 & 174,00 & & & \\
\hline & S_96 (IV) & 6 & 131,67 & 30,50 & 82,00 & 161,00 & & & \\
\hline & $\mathrm{R}+\mathrm{S} \_16(\mathrm{~V})$ & 6 & 128,17 & 19,65 & 107,00 & 152,00 & & & \\
\hline & $\mathrm{R}+\mathrm{S} \_96(\mathrm{VI})$ & 6 & 136,50 & 17,52 & 115,00 & 167,00 & & & \\
\hline & Total & 36 & 133,58 & 27,90 & 81,00 & 209,00 & & & \\
\hline \multirow{7}{*}{ D-dimer } & Control (I) & 6 & 16,03 & 21,27 & 0,53 & 57,60 & \multirow{7}{*}{0,938} & \multirow{7}{*}{0,409} & \multirow{7}{*}{0,933} \\
\hline & $\mathrm{R}(\mathrm{II})$ & 6 & 11,36 & 8,52 & 1,40 & 24,12 & & & \\
\hline & S_16 (III) & 6 & 18,71 & 14,23 & 2,26 & 39,71 & & & \\
\hline & S_96 (IV) & 6 & 14,07 & 14,86 & 2,27 & 42,03 & & & \\
\hline & $\mathrm{R}+\mathrm{S} \_16(\mathrm{~V})$ & 6 & 11,99 & 8,35 & 2,55 & 21,62 & & & \\
\hline & $\mathrm{R}+\mathrm{S} \_96(\mathrm{VI})$ & 6 & 12,13 & 22,17 & $-5,57$ & 58,77 & & & \\
\hline & Total & 36 & 13,99 & 15,17 & $-5,57$ & 58,77 & & & \\
\hline
\end{tabular}

${ }^{*}$ SD: standard deviation.

the aim of reversing the blockage effect caused by these agents, acetylcholinesterase inhibitors have been used for many years but have important disadvantages such as residual block and hemodynamic side effects. Sugammadex is a gamma cyclodextrin derivative that is a new-generation reversal agent used to end the effects of nondepolarizing neuromuscular blockers (vecuronium and rocuronium). Its method of effect is to form a complex with muscle relaxants in circulation and at the nerve-muscle junctions, to end their effect [1]. Studies on sugammadex have shown that the medication is safe even at deep block levels and provides extubation conditions and a range of complications during waking are encountered less often $[1,8]$. The cardiovascular side effects seen with traditional reversal agents are not observed with sugammadex and this is an important advantage $[2,5]$. Sugammadex is a reliable and well-tolerated medication with increasing use in recent years [9-11]. It has been used in Europe since 2008 and in Japan since 2010, while it awaits approval from the Food and Drug Administration (FDA) in the USA [7]. In spite of many superior properties that have been reported it has been known that with sugammadex some changes in coagulation parameters occur without documented clinical consequences. There is still controversy about the relationship between sugammadex and bleeding $[5,6]$.

Hemostasis mechanisms during surgical procedures are directed at stopping bleeding and preventing the formation of thrombosis. In the preoperative period no matter how much hemostasis tests are recommended to identify coagulation 
TABLE 4: Descriptive statistics for AST, ALT, and albumin parameters according to group and administered agents.

\begin{tabular}{|c|c|c|c|c|c|c|c|c|c|}
\hline \multirow{2}{*}{ Parameters } & \multirow{2}{*}{ Groups } & \multirow{2}{*}{$N$} & \multirow{2}{*}{ Mean } & \multirow{2}{*}{$\mathrm{SD}^{*}$} & \multirow{2}{*}{ Min } & \multirow{2}{*}{ Max } & \multicolumn{3}{|c|}{$p$ values } \\
\hline & & & & & & & $S$ & $\mathrm{R}$ & $\mathrm{S} \times \mathrm{R}$ \\
\hline \multirow{7}{*}{ AST } & Control (I) & 6 & 122,83 & 50,72 & 81,00 & 203,00 & \multirow{7}{*}{0,717} & \multirow{7}{*}{0,347} & \multirow{7}{*}{0,881} \\
\hline & $\mathrm{R}(\mathrm{II})$ & 6 & 153,50 & 41,65 & 82,00 & 194,00 & & & \\
\hline & S_16 (III) & 6 & 146,00 & 83,66 & 88,00 & 309,00 & & & \\
\hline & S_96 (IV) & 6 & 145,50 & 67,19 & 95,00 & 272,00 & & & \\
\hline & $\mathrm{R}+\mathrm{S} \_16(\mathrm{~V})$ & 6 & 178,67 & 111,80 & 95,00 & 353,00 & & & \\
\hline & $\mathrm{R}+\mathrm{S} \_96(\mathrm{VI})$ & 6 & 151,33 & 56,28 & 91,00 & 209,00 & & & \\
\hline & Total & 36 & 149,64 & 69,10 & 81,00 & 353,00 & & & \\
\hline \multirow{7}{*}{ ALT } & Control (I) & 6 & 60,17 & 19,36 & 40,00 & 97,00 & \multirow{7}{*}{0,834} & \multirow{7}{*}{0,301} & \multirow{7}{*}{0,989} \\
\hline & $\mathrm{R}(\mathrm{II})$ & 6 & 69,50 & 37,75 & 32,00 & 134,00 & & & \\
\hline & S_16 (III) & 6 & 54,50 & 16,47 & 31,00 & 78,00 & & & \\
\hline & S_96 (IV) & 6 & 59,17 & 19,06 & 39,00 & 91,00 & & & \\
\hline & $\mathrm{R}+\mathrm{S} \_16(\mathrm{~V})$ & 6 & 63,50 & 17,14 & 33,00 & 83,00 & & & \\
\hline & $\mathrm{R}+\mathrm{S} \_96(\mathrm{VI})$ & 6 & 65,83 & 25,72 & 34,00 & 106,00 & & & \\
\hline & Total & 36 & 62,11 & 22,55 & 31,00 & 134,00 & & & \\
\hline \multirow{7}{*}{ Albumin } & Control (I) & 6 & 2,61 & 0,47 & 2,10 & 3,60 & \multirow{7}{*}{0,184} & \multirow{7}{*}{0,505} & \multirow{7}{*}{0,383} \\
\hline & $\mathrm{R}(\mathrm{II})$ & 6 & 2,39 & 0,50 & 1,70 & 3,10 & & & \\
\hline & S_16 (III) & 6 & 2,93 & 0,45 & 2,10 & 3,40 & & & \\
\hline & S_96 (IV) & 6 & 2,66 & 0,53 & 1,80 & 3,30 & & & \\
\hline & $\mathrm{R}+\mathrm{S} \_16(\mathbf{V})$ & 6 & 2,69 & 0,45 & 1,90 & 3,20 & & & \\
\hline & $\mathrm{R}+\mathrm{S} \_96(\mathrm{VI})$ & 6 & 2,84 & 0,30 & 2,40 & 3,30 & & & \\
\hline & Total & 36 & 2,69 & 0,46 & 1,70 & 3,60 & & & \\
\hline
\end{tabular}

*SD: standard deviation.

AST: aspartate aminotransferase.

ALT: alanine aminotransferase.

disorders and determine postoperative hemorrhage risk, routine coagulation tests may not always be possible. However, in patients with positive hemorrhage history these tests are significant to a greater degree $[12,13]$. In a study short-term (<30 min) prolongation of activated partial thromboplastin time (aPTT) was shown to follow doses of 4 and $16 \mathrm{mg} \mathrm{kg}^{-1}$ sugammadex [14]. In research on healthy volunteers by de Kam et al. to investigate the effect of sugammadex on coagulation factors and platelet aggregation, 4 and $16 \mathrm{mg} \mathrm{kg}^{-1}$ doses of sugammadex caused a dose-related, limited, and temporary lengthening of aPTT and PT that was not clinically significant [15]. Another research, again by de Kam et al., on 26 healthy volunteers showed that sugammadex taken together with aspirin did not have a significant effect clinically in terms of reducing platelet aggregation [16]. However, it must be recalled that when PLT count and coagulation parameters are normal, hemorrhage due to reasons such as platelet function disorders, hereditary hemorrhagic disorders, von Willebrand disease, and Factor XIII deficiency may still be seen $[17,18]$. MPV plays a role as an indicator of platelet activation [19]. Though the relationship between MPV and platelet count is not very clear, it is reported that an increase in MPV is accompanied by a reduction in platelet counts [20]. In our research we did not find a significant change in PLT and MPV counts in any of the groups given low or high dose sugammadex compared with the control group (Table 1). Again in terms of PT, aPTT, fibrinogen, and D-dimer levels, there was no significant difference between the groups (Tables 2 and 3). Some publications have reported that, though low, there is a potential risk of hemorrhage in the postoperative period due to the minor and temporary lengthening effect of sugammadex administered at the end of the surgical procedure [21, $22]$. From the point of view of sugammadex and hemorrhagic complications, the European Medicines Agency researched two possible hemorrhagic complications and determined that "obtained proof shows there is an effect of sugammadex on bleeding parameters such as aPTT and PT" [23]. According to information given by the European Medicines Agency on the product characteristics of sugammadex, doses of 4 and $16 \mathrm{mg} \mathrm{kg}^{-1}$ resulted in maximum mean prolongations of the activated partial thromboplastin time by 17 and $22 \%$, respectively, and prothrombin time by 11 and $22 \%$, respectively. These limited mean aPTT and PT prolongations were of short duration ( $\leq 30$ minutes). Again as stated in the same report, an increased risk of bleeding cannot be excluded in patients with hereditary vitamin $\mathrm{K}$ dependent clotting factor deficiencies and with preexisting coagulopathies and using anticoagulants who receive a dose of $16 \mathrm{mg} \mathrm{kg}^{-1}$ sugammadex. Administrators of anesthesia evaluate the risk-benefit ratio for patients with these types of risk factors and monitor these patients closely for hemostasis. In vitro studies have reported that there may be a pharmacodynamic interaction with vitamin $\mathrm{K}$ antagonists, unfractionated heparin, low molecular weight heparinoids, rivaroxaban, and dabigatran [4]. Other studies 
on the topic of sugammadex and laboratory tests have shown that, other than the exceptions of progesterone levels and coagulation parameters (aPTT, PT), sugammadex was not reported to have any interactions in other laboratory tests. These interactions were reported at similar intervals to serum concentrations obtained after administration of $16 \mathrm{mg} \mathrm{kg}^{-1}$ sugammadex. In addition as sufficient studies have not been completed with patients, it is not clear whether the findings are clinically significant or not $[5,24,25]$. In recent times as clinical results related to sugammadex have begun to be reported, information must be added that in the minutes immediately after administration a lengthened clotting time has been noticed [26]. In our study where groups were given sugammadex alone or after rocuronium with low or high dose, we did not find any significant change in terms of coagulation or fibrinolytic system parameters in any of the groups given sugammadex compared to the control group. Raft et al., in a retrospective study observing the effect of sugammadex on amount of bleeding in drains and dressings after laparotomy, found that in the group using sugammadex after a variety of cancer surgeries with high hemorrhagic potential no significant difference was observed in postoperative coagulation parameters compared to preoperative values and reported that there was no statistically significant difference in amount of bleeding after surgery. With these findings the researchers recommended that new studies about hemostasis should be completed with doses of sugammadex higher than 2 and $4 \mathrm{mg} \mathrm{kg}^{-1}$, primarily on patients with coagulation disorders [6]. In situations where the liver, a very important organ in the hemostatic system, is affected, many disorders are observed such as thrombocytopenia, platelet function defects, reduced levels of coagulation factors in circulation, and reduced levels of proteins playing a role in fibrinolysis [27]. In our study when the markers of liver function of AST, ALT, and albumin levels are examined, there was no difference found between the groups (Table 4). Staals et al. in a study of patients with renal failure, found sugammadex had no significant effect on AST, ALT, gamma glutamyl transferase levels and PLT counts compared to the control group [28]. In 2014 Rahe-Meyer et al., in a study of patients undergoing joint surgery on the hip or knee, compared the aPTT and PT levels of patients given sugammadex, neostigmine with glycopyrrolate, or atropine or placebo/spontaneous recovery and found limited levels of increase and reported that there was no other increase in incidence of bleeding [21]. Schaller and Fink in an evidence-based compilation reported that if there is a situation that causes risk of bleeding or that may be revealed by not taking extra precautions with sugammadex, the anticoagulant effects of sugammadex may become clear clinically in such situations. They also stated that for administration in such patient groups the bleeding risk of sugammadex must be balanced by superior individual benefits [7]. The aim of our study was to evaluate the acute effect of sugammadex on synthesis ability of the liver. Serum values of AST, ALT, and albumin were used for determination of the synthesis ability. Our results showed that sugammadex has not any deleterious effect on synthesis ability of the liver. We think that in order to perform more comprehensive investigation of sugammadex on liver functions, the half-life of ALT, AST, albumin, and other proteins synthesized in liver should be considered and their consequential serum values should be determined.

\section{Conclusion}

In conclusion, our research found that low and high doses of sugammadex in rats had no significant effect on PT, aPTT, Ddimer, fibrinogen, AST, ALT, albumin, PLT, and MPV levels. However, the bleeding risk related to surgery may be due to silent hematological diseases or medications and herbal preparations used by patients and we believe it is necessary to investigate sugammadex in more detail in such situations.

\section{Ethical Approval}

This experimental study was approved by Ondokuz Mayis University Animal Care and Ethics Committee (2013/06), Samsun, Turkey.

\section{Conflict of Interests}

The authors declare no conflict of interests.

\section{Acknowledgments}

The authors would like to thank Associate Professor Dr. Soner Çankaya, Ordu University Ordu/Turkey, for helping in statistical analysis. This study was supported by Ordu University Scientific Research Projects Coordination Department (Project no. 2014; AR-1337).

\section{References}

[1] A. Bom, F. Hope, S. Rutherford, and K. Thomson, "Preclinical pharmacology of sugammadex," Journal of Critical Care, vol. 24, no. 1, pp. 29-35, 2009.

[2] L. M. Staals, H. D. de Boer, J. van Egmond et al., "Reversal of rocuronium-induced neuromuscular block by sugammadex is independent of renal perfusion in anesthetized cats," Journal of Anesthesia, vol. 25, no. 2, pp. 241-246, 2011.

[3] T. Gaszynski, T. Szewczyk, and W. Gaszynski, "Randomized comparison of sugammadex and neostigmine for reversal of rocuronium-induced muscle relaxation in morbidly obese undergoing general anaesthesia," British Journal of Anaesthesia, vol. 108, no. 2, pp. 236-239, 2012.

[4] http://www.ema.europa.eu/docs/en_GB/document_library/ EPAR_-_Product_Information/human/000885/WC500052310 .pdf.

[5] T. M. Hemmerling, C. Zaouter, G. Geldner, and D. Nauheimer, "Sugammadex-a short review and clinical recommendations for the cardiac anesthesiologist," Annals of Cardiac Anaesthesia, vol. 13, no. 3, pp. 206-216, 2010.

[6] J. Raft, J.-F. Betala Belinga, G. Jurkolow, E. Desandes, D. Longrois, and C. Meistelman, "Clinical evaluation of post-surgical bleeding after a sugammadex injection," Annales Francaises d'Anesthesie et de Reanimation, vol. 30, no. 10, pp. 714-717, 2011.

[7] S. J. Schaller and H. Fink, "Sugammadex as a reversal agent for neuromuscular block: an evidence-based review," Core Evidence, vol. 8, pp. 57-67, 2013. 
[8] G. Cammu, P.-J. De Kam, K. De Graeve et al., "Repeat dosing of rocuronium $1.2 \mathrm{mg} \mathrm{kg}^{-1}$ after reversal of neuromuscular block by sugammadex $4.0 \mathrm{mg} \mathrm{kg}^{-1}$ in anaesthetized healthy volunteers: a modelling-based pilot study," British Journal of Anaesthesia, vol. 105, no. 4, pp. 487-492, 2010.

[9] I. F. Sorgenfrei, K. Norrild, P. B. Larsen et al., "Reversal of rocuronium-induced neuromuscular block by the selective relaxant binding agent sugammadex: a dose-finding and safety study," Anesthesiology, vol. 104, no. 4, pp. 667-674, 2006.

[10] H. J. M. Lemmens, M. I. El-Orbany, J. Berry, J. B. Morte Jr., and G. Martin, "Reversal of profound vecuronium-induced neuromuscular block under sevoflurane anesthesia: sugammadex versus neostigmine," BMC Anesthesiology, vol. 10, article 15, 2010.

[11] R. K. Mirakhur, "Sugammadex in clinical practice," Anaesthesia, vol. 64, no. 1, pp. 45-54, 2009.

[12] N. Bhasin and R. I. Parker, "Diagnostic outcome of preoperative coagulation testing in children," Pediatric HematologyOncology, vol. 31, no. 5, pp. 458-466, 2014.

[13] P. Gabriel, X. Mazoit, and C. Ecoffey, "Relationship between clinical history, coagulation tests, and perioperative bleeding during tonsillectomies in pediatrics," Journal of Clinical Anesthesia, vol. 12, no. 4, pp. 288-291, 2000.

[14] E. Sokół-Kobielska, "Sugammadex-indications and clinical use," Anaesthesiology Intensive Therapy, vol. 45, no. 2, pp. 106110, 2013.

[15] P. J. de Kam, P. Grobara, M. Prohn et al., "Effects of sugammadex on activated partial thromboplastin time and prothrombin time in healthy subjects," International Journal of Clinical Pharmacology and Therapeutics, vol. 52, no. 3, pp. 227-236, 2014.

[16] P.-J. de Kam, R. El Galta, A. C. Kruithof et al., "No clinically relevant interaction between sugammadex and aspirin on platelet aggregation and coagulation parameters," International Journal of Clinical Pharmacology and Therapeutics, vol. 51, no. 12, pp. 976-985, 2013.

[17] M. B. C. Koh and B. J. Hunt, "The management of perioperative bleeding," Blood Reviews, vol. 17, no. 3, pp. 179-185, 2003.

[18] M. Thomas and M. D. Habermann, "Hematology," in Mayo Clinic Internal Medicine; Concise Textbook, T. M. Habermann and A. K. Ghosh, Eds., pp. 379-383, CRC Press, 2008.

[19] B. T. Somuk, H. Soyalıç, S. Koc, L. Gürbüzler, S. Doğru, and A. Eyibilen, "Mean platelet volume as an inflammatory marker of chronic otitis media with effusion," International Journal of Pediatric Otorhinolaryngology, vol. 78, no. 11, pp. 1958-1960, 2014.

[20] S. G. Chu, R. C. Becker, P. B. Berger et al., "Mean platelet volume as a predictor of cardiovascular risk: a systematic review and meta-analysis," Journal of Thrombosis and Haemostasis, vol. 8, no. 1, pp. 148-156, 2010.

[21] N. Rahe-Meyer, H. Fennema, S. Schulman et al., "Effect of reversal of neuromuscular blockade with sugammadex versus usual care on bleeding risk in a randomized study of surgical patients," Anesthesiology, vol. 121, no. 5, pp. 969-977, 2014.

[22] M. Carron, "Effects of sugammadex on coagulation: it does not represent a bleeding risk in surgicalpatients," International Journal of Clinical Pharmacology and Therapeutics, vol. 52, no. 9, p. 824, 2014.

[23] S. J. A. Gold and N. J. N. Harper, "The place of sugammadex in anaesthesia practice," Trends in Anaesthesia and Critical Care, vol. 2, no. 1, pp. 4-9, 2012.
[24] S. J. Brull and M. Naguib, "Selective reversal of muscle relaxation in general anesthesia: focus on sugammadex," Drug Design, Development and Therapy, no. 3, pp. 119-129, 2009.

[25] L. P. H. Yang and S. J. Keam, "Sugammadex: a review of its use in anaesthetic practice," Drugs, vol. 69, no. 7, pp. 919-942, 2009.

[26] T. Fuchs-Buder, C. Meistelman, and J. Raft, "Sugammadex: clinical development and practical use," Korean Journal of Anesthesiology, vol. 65, no. 6, pp. 495-500, 2014.

[27] T. Lisman, S. H. Caldwell, A. K. Burroughs et al., "Hemostasis and thrombosis in patients with liver disease: the ups and downs," Journal of Hepatology, vol. 53, no. 2, pp. 362-371, 2010.

[28] L. M. Staals, M. M. J. Snoeck, J. J. Driessen, E. A. Flockton, M. Heeringa, and J. M. Hunter, "Multicentre, parallel-group, comparative trial evaluating the efficacy and safety of sugammadex in patients with end-stage renal failure or normal renal function," British Journal of Anaesthesia, vol. 101, no. 4, pp. 492-497, 2008. 


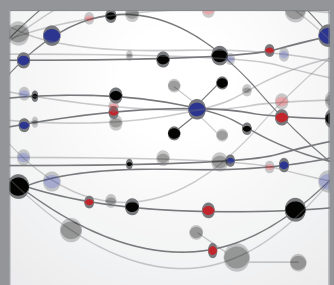

The Scientific World Journal
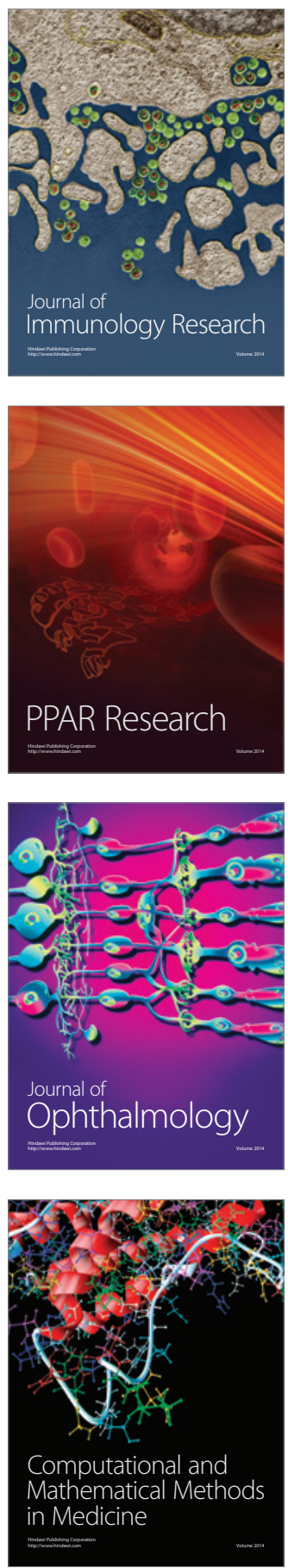

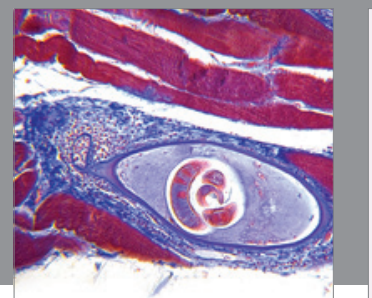

Gastroenterology

Research and Practice
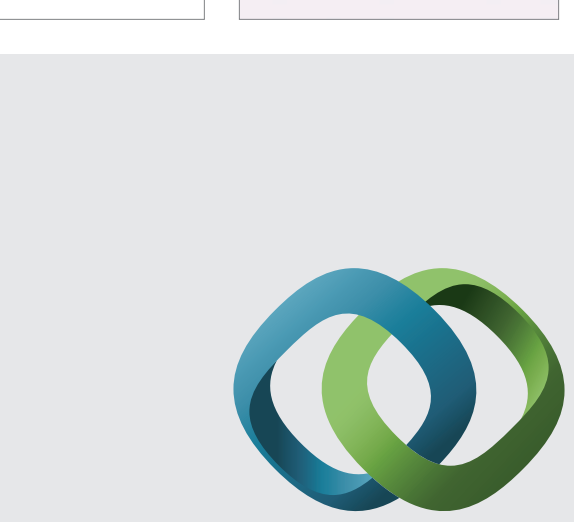

\section{Hindawi}

Submit your manuscripts at

http://www.hindawi.com
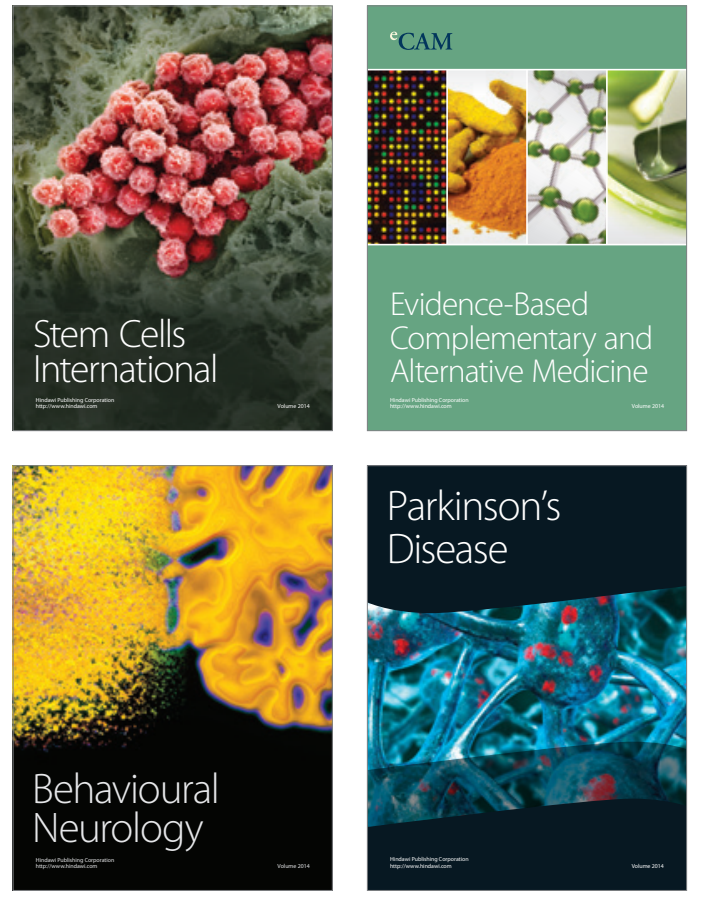
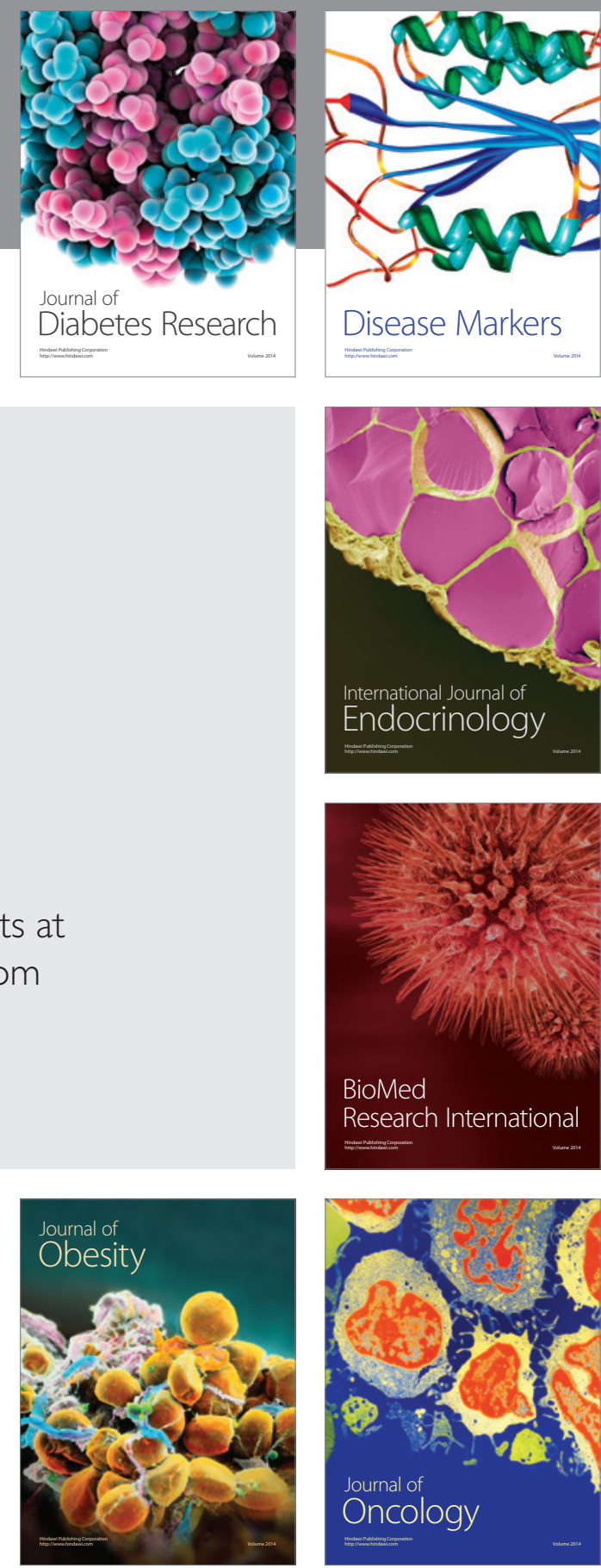

Disease Markers
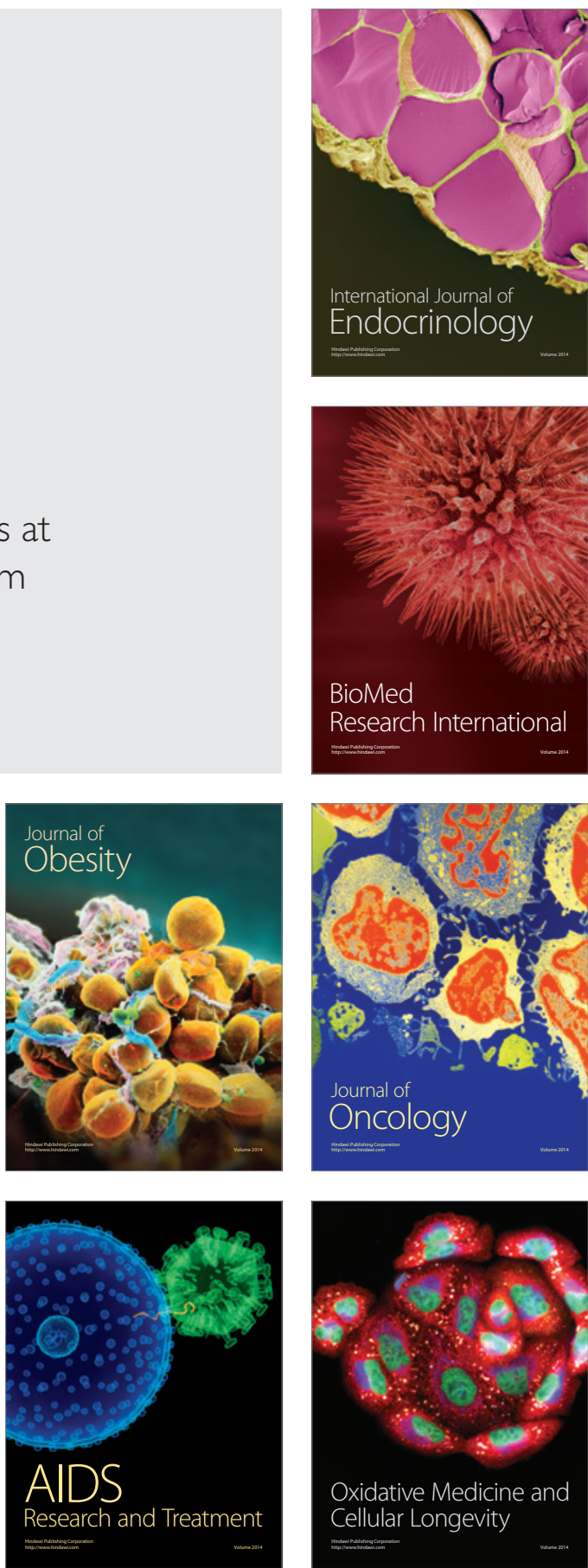